\title{
Development and validation of a magnetic resonance imaging-based nomogram for predicting invasive form of placental accreta spectrum disorders: a retrospective study
}

\author{
Qiang $\mathrm{Li}^{1}$, Hang Zhou ${ }^{1}$, Kefeng Zhou ${ }^{1}$, Jian $\mathrm{He}^{1}$, Zhihao $\mathrm{Shi}^{1}$, Yimin Dai $^{1}$, Zhiqun Wang ${ }^{1}$, \\ and Yali $\mathrm{Hu}^{2}$ \\ ${ }^{1}$ Nanjing Drum Tower Hospital, Clinical College of Nanjing Medical University \\ ${ }^{2}$ Nanjing Drum Tower Hospital, Clinical College of Nanjing Medical University
}

May 5, 2020

\begin{abstract}
Objective To create an MRI-based nomogram for the prediction of PAS disorders Design Retrospective study from February 2014 to July 2018. Setting A tertiary hospital in Nanjing. Population A total of 183 patients with "uncertain ultrasound diagnosis", further evaluated by MRI between February 2014 and July 2018, were included. Methods The final degree of invasion was confirmed during Cesarean section. Two radiologists evaluated a new sign named as "loss of double-line sign" and seven previous described MRI signs associated with PAS disorders. The nomogram was constructed by risk factors identified by logistic regression analysis. Main outcome measures The accuracy and discriminative ability of the nomogram were measured by concordance index(C-index) and calibration curve. Results In primary cohort of 118 patients, $50.0 \%$ of patients suffered from placenta increta and percreta. Logistic regression revealed previous cesarean deliveries (OR 3.3, 95\%CI 1.2-9.3), disorganized abnormal placenta vascularity (OR 3.4, 95\% CI 1.1-10.5), abnormal uterine bulging (OR 4.0, 95\%CI 1.5-10.7) and loss of doubleline sign (OR 9.5, 95\% CI 3.1-29.5) as independent risk factors associated with invasive form of PAS disorders. These factors were selected for the construction of the nomogram. The C-index of the nomogram was 0.85 for internal validantion and 0.84 for external validantion. Calibration curve of the nomogram showed good agreement with predicted risk and actual observation for both primary and validation cohort. Conclusion Nomogram based on MRI signs can be a useful adjunct for clinical staging of patients with "uncertain ultrasound diagnosis", which showed good accuracy and discriminative ability.
\end{abstract}

\section{Hosted file}

3Maintext.doc available at https://authorea.com/users/301457/articles/431275-developmentand-validation-of-a-magnetic-resonance-imaging-based-nomogram-for-predicting-invasiveform-of-placental-accreta-spectrum-disorders-a-retrospective-study

\section{Hosted file}

Table 1.doc available at https://authorea.com/users/301457/articles/431275-development-andvalidation-of-a-magnetic-resonance-imaging-based-nomogram-for-predicting-invasive-formof-placental-accreta-spectrum-disorders-a-retrospective-study

\section{Hosted file}

Table 2.doc available at https://authorea.com/users/301457/articles/431275-development-andvalidation-of-a-magnetic-resonance-imaging-based-nomogram-for-predicting-invasive-formof-placental-accreta-spectrum-disorders-a-retrospective-study

\section{Hosted file}


Figure 1.doc available at https://authorea.com/users/301457/articles/431275-development-andvalidation-of-a-magnetic-resonance-imaging-based-nomogram-for-predicting-invasive-formof-placental-accreta-spectrum-disorders-a-retrospective-study

\section{Hosted file}

Figure 2.jpg available at https://authorea.com/users/301457/articles/431275-development-andvalidation-of-a-magnetic-resonance-imaging-based-nomogram-for-predicting-invasive-formof-placental-accreta-spectrum-disorders-a-retrospective-study 